\title{
SUSTAINABLE POST-CRISIS CAPITAL MARKET RECOVERY - THE CASE OF EURO STOXX 50
}

\author{
Vladimir Tsenkov ${ }^{1}$ \\ Kiril Mirchev ${ }^{2}$
}

Received: November 28, 2018 / Revised: January 10, 2019/ Accepted: March 16, 2019

(C) Association of Economists and Managers of the Balkans, 2019

\begin{abstract}
In the context of the last global financial crisis of 2008 and the subsequent post-crisis recovery of international capital markets, the question of the sustainability of that recovery process has been raised. To test that we use the presence and the magnitude of manifestation of market phenomena called volatility paradox. This paradox raises the question whether its presence in the conditions of the sustainable ascending market trend during the post-crisis recovery is not a signal marking the potential for a new forthcoming financial crisis. Studying the periods before and after the 2008 global financial crisis can give us a pattern market dynamics of volatility paradox manifestation in the pre-crisis period which can be traced out in the post-crisis period. If the existence of volatility paradox is possible, it should be seen in the pre-crisis period up to 2008. Its power of manifestation during this period should serve as a benchmark for verifying the post-crisis VP, both as an existence and as a size of manifestation compared to the demonstrated until 2008. The empirical results show that the market dynamics of the EURO STOXX 50 index proves the existence of volatility paradox, both in the pre-and the post-crisis period. For the same two periods for the shares included in the EURO STOXX 50 the existence of volatility paradox is not detected. Moreover, the shares of the EURO STOXX 50 index show higher market efficiency in the context of EMH in comparison with the index itself. The empirical research was made using market dynamics of the EURO STOXX 50 index and the shares it's incorporated in the period 2005 - 2017. In this research, we use the daily returns of the explored index and shares whose volatility was modeled by TGARCH models.
\end{abstract}

Keywords: Efficient Market Hypothesis, volatility paradox, information efficiency and asymmetry, TGARCH, EURO STOXX 50.

\section{JEL Classification C32 • G01 • G14 • G15}

This paper was presented at the Second International Scientific Conference on IT, Tourism, Economics, Management and Agriculture - ITEMA 2018 - November 8, 2018, Graz, Austria, www.itema-conference.com

Vladimir Tsenkov

v.tsenkov@yahoo.com

South-West University “Neofit Rilski”, Faculty of Economics, 60 Ivan Mihailov str., 2700 Blagoevgrad, Bulgaria South-West University “Neofit Rilski”, Faculty of Economics, 60 Ivan Mihailov str., 2700 Blagoevgrad, Bulgaria 


\section{INTRODUCTION}

The Efficient Market Hypothesis (EMH) postulates that changes in the prices of financial assets are independent and unpredictable so that at each moment the market price includes all relevant information. In that matter, the market informational efficiency can be questioned not only in general about the rationality of all predictions concerning future market dynamics, but also when it comes to the ability for forecast the first signals of a forthcoming crisis. In the context of the last global financial crisis of 2008 and the subsequent post-crisis recovery of international capital markets, the question of the sustainability of that recovery process has been raised. Searching for indicators of future capital markets instability, the importance of market phenomena such as volatility paradox has emerged. This paradox raises the question whether its presence in the conditions of the sustainable ascending market trend during the post-crisis recovery is not a signal for a potential for a new forthcoming financial crisis.

Another important aspect of a volatility paradox study is its micro- and macro-level of manifestation, i.e. at the level of the market index and at the level of market dynamics of the shares included in the same index. In this way, not only can we put to the test the validity of the Efficient Market Hypothesis in direction of separation of the market efficiency in micro- and macro- aspect, but we can put to the test assumption that market phenomena such volatility paradox can defer as a manifestation depending on the scale to which they refer. This way we could also check the degree in which volatility paradox can be used as a reliable indicator for future crisis.

\section{LITERATURE REVIEW}

The connection be twin the phase of the business cycle and market volatility had been tested and confirmed mainly for the U.S. markets with the finding that financial crises are associated with high volatility (Schwert, 1989, 1990; Hamilton and Lin, 1996; Fornari and Mele, 2009; Corradi et al., 2013). The conceptual link between low volatility and crises can be traced back to Hayek's (1960) assumption that risk cycle is separate from the business cycle and that low risk encourages risk-taking. Minsky's (1992) develops further that assumption and suggests that economic agents interpret the presence of a low risk environment as an incentive to increase risk-taking, which in turn may lead to a crisis. That way the Minsky hypothesis is establishing the direct connection be twin presence of low market volatility and a high potential for eventual crisis, as the low volatility conditions leads in the end, or encourage, the acceleration of the market potential for turmoil and crisis. Bhattacharya et al. (2015) link Minsky's assumption for investors' riskier behavior during low volatility conditions with their borrowing. In their framework, the expectations of creditors follow those of the investors and they are more willing to give them funds. As a consequence, the borrowing increases but not the risk premium. This contributes to the increment of relatively riskier projects in the portfolios of the investors. Although this increases the loss potential of the portfolios, expected default and credit spreads do not adjust commensurately. That way when the positive market trend reverses default is higher than it would otherwise be and the consequences for financial stability are more severe. Danielsson, Valenzuela, and Zer (2016) study the effects of volatility on financial crises using a database for over 200 years. To study the effect of the impact of high and low volatility on agents' decisions they decompose volatility into high and low deviations from its trend. They found that volatility itself is not a significant predictor of banking crises, but unusually high and low volatilities are. Especially low volatility, the presence of which is directly linked with the forming of credit build-ups, indicates that agents take more risk in periods of low risk. This finding confirmed Minsky's instability hypothesis and his main statement that "stability is destabilizing". This way we can conclude that low volatility induces risk-taking, 
which leads to riskier investments, and when those turns to loss a crisis follows. This finding becomes more important over time as their observation on stock markets over 221-year sample show growing importance of stock markets over time which leads to growing importance of the relationship between volatility gap and the incidence of a crisis.

\section{ECONOMETRIC METHODOLOGY FRAMEWORK}

For the purpose of the survey the data from the index and its shares are divided into two periods. The pre-crisis period shall cover the interval until the highest value of the index is reached before the start of the global financial crisis of 2008. The period covers the time interval of 03.01.2005. until 16.7.2007. And respectively, the post-crisis period covers the time interval from 10.3.2009. until 9.3.2017 during which time the index reached the lowest level and started post-crisis recovery.

For the econometric modeling of the EURO STOXX 50 index and its shares, daily data and the return on the basis of the following formula are used:

$$
r_{t}=\ln \frac{P_{t}}{P_{t-1}}
$$

Where:

$r_{t}$ - return at the moment $\mathrm{t}$;

$P_{t}$ and $P_{t-1}$ - index or shares values for the moments $t$ and $t-1$.

Regarding the econometric modeling of volatility, the Threshold GARCH (TGARCH) with Student-t distribution are used (2):

$$
\sigma_{t}^{2}=w+\sum_{j=1}^{q} \beta_{j} \sigma_{t-j}^{2}+\sum_{i=1}^{p} \alpha_{i} \epsilon_{t-i}^{2}+\sum_{k=1}^{r} \gamma_{k} \epsilon_{t-k}^{2} I_{t-k}
$$

Where:

$P_{t}=1$ if $\varepsilon_{t}<0$ and $P_{t}=0$ if $\varepsilon_{t} \geq 0$

$\gamma$ - leverage coefficient representing the impact of the negative market news.

The volatility paradox (VP) confirmation analysis should go in the context of the efficient market hypothesis (EMH). According to this hypothesis, the market phenomenon in question should not exist and have predictive power. The basic assumption of VP is the existence of negative connection between market returns and volatility. When markets rise, i.e. there is a positive market trend and predominantly positive news about market returns, its volatility should be lower. The opposite behavior is requiring during a negative market trend and negative news. In order to capture this effect within the econometric methodology based on the TGARCH modeling of volatility the value of the leverage coefficient covering asymmetric incorporation of market information(news) should be: A) Negative, in the conditions of a rising market trend; B) Positive of relatively high value, at a downward market.

Splitting a survey period into two sub-periods not only facilitates the process of clearer identification of the impact of the 2008 global financial crisis but also give us a pattern market dynamics of VP manifestation in the pre-crisis period which can be traced out in the post-crisis period. If the existence of VP is possible, it should be seen in the pre-crisis period up to 2008. Its power of manifestation during this period should serve as a benchmark for verifying the post-crisis VP, both as an existence and as a size of manifestation compared to the demonstrated until 2008. 
The results of the TGARCH models used for the shares are averaged for the purpose of direct comparison with the respective coefficients registered for the EURO STOXX 50 index. In order to better identify trends in the volatility of the shares, the TGARCH models used the database form ten leading shares in the EURO STOXX 50 with the highest capitalization over the studied period.

\section{EMPIRICAL ANALYSIS}

\subsection{RETURNS SERIAL AUTOCORRELATIONS}

The econometric analysis of the existence of the volatility paradox begins with an analysis for the presence of autocorrelation dependences in the return dynamics of the index and its shares. Statistically significant autocorrelation dependencies would determine the dynamics of return as inefficient in the context of EMH. Given the fact that the volatility paradox itself represents the same inefficiency, it would raise the question of whether its manifestation was not originally determined by the inefficiency of returns or the paradox is market phenomena related only with the market volatility. We find this an important moment for clarification, especially when the presence and manifestation of the volatility paradox are analyzed in terms of its prognostic capabilities as an early indicator of future crises.

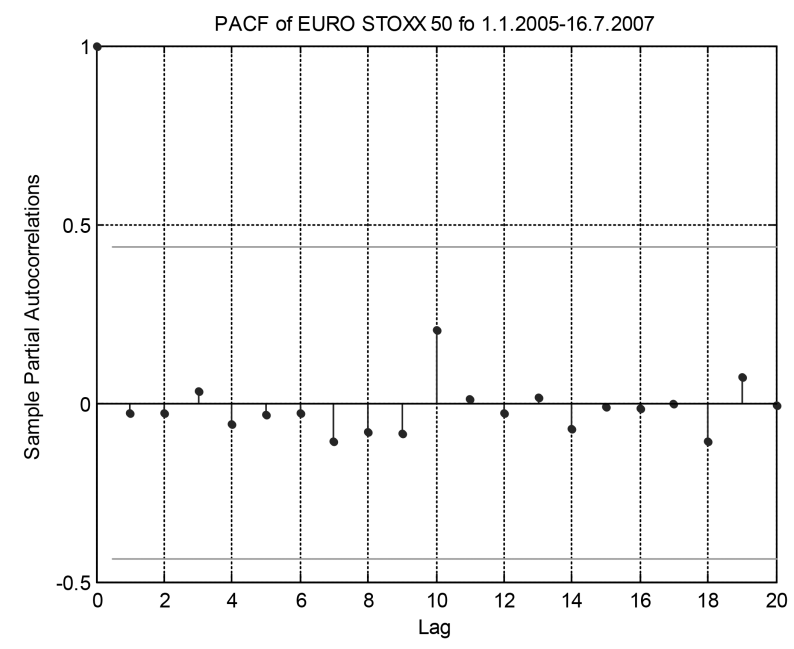

Figure 1: Graph of partial autoregressive (PACF) of index for pre-crisis period

In the context of EMH for the pre-crisis period (Figure 1), we register excellent results of PACF with values close to zero. The only exception is at lag ten with a value of 0.2 , but it is statistically insignificant. There are no long-term autocorrelation dependences, whether in a positive or negative direction. All of this leads to confirmation of the ,weak" form of the hypothesis over the period. Despite the steady rise in the index, as well as its share values over the period, with the market efficiently incorporating the information, there is no possibility of gaining the extra-market returns from the predictability of the dynamism of the market return.

In the post-crisis period, the market dynamics achieve its performance, as before the crisis with very close to zero values (Figure 2). Again, there is a free movement of prices, there are no serial correlation trends in one direction, which fully confirms the hypothesis in its ,weak" form and shows that we have market efficiency in forming values in the index by reflecting of any available information at the time. 


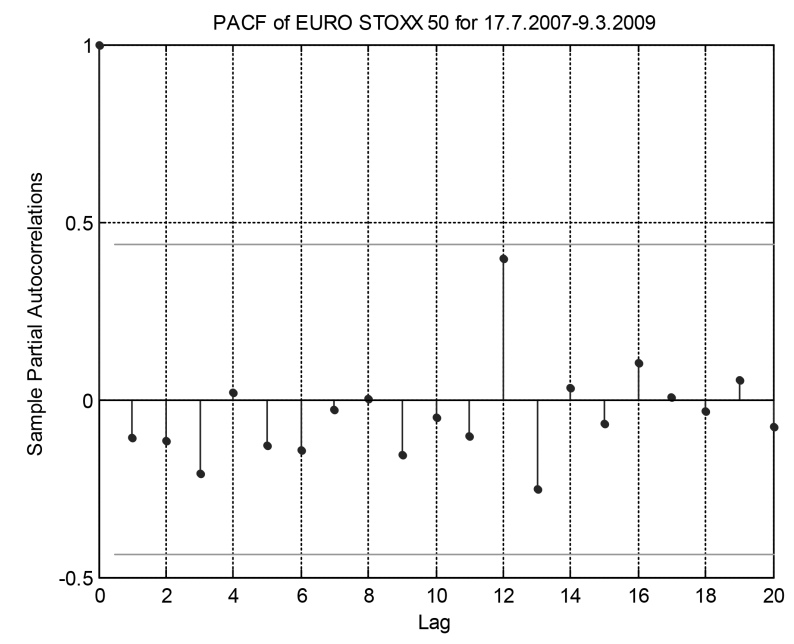

Figure 2 - Graph of partial autoregressive (PACF) of index for post-crisis period

The two subperiods the PACF testing shows results for the index that confirm the „weak" form of the EMH for the overall performance of the EURO STOXX 50 index. The next stage of verification is at the shares level, where we test the two sub-periods for the existence of statically significant autocorrelations.

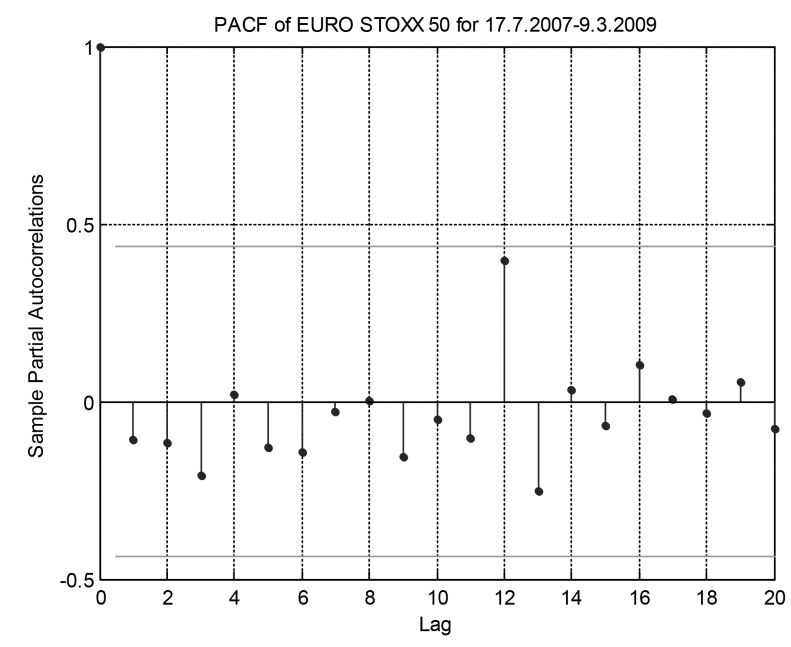

Figure 3: Graph of partial autoregressive (PACF) of shares for pre-crisis period

In analyzing the graph of partially autoregressive (PACF) for pre-crisis period of the shares in the index (Figure 3) the following conclusions can be drawn. The results are identical to those for the EURO STOXX 50. There are no statically significant autocorrelation dependencies, whether in a positive or negative direction. This is a sign of free movement of prices or so-called random walk, which is directly related to the assumptions of the ,weak" form of the EMH. The results shown are increased between the tenth and the fourteenth lag, but again within the allowable range, with no crossing of the limits of significance. The period based on the results shown can be defined as relatively stable and confirming the thesis that the market is effective at a micro level. 


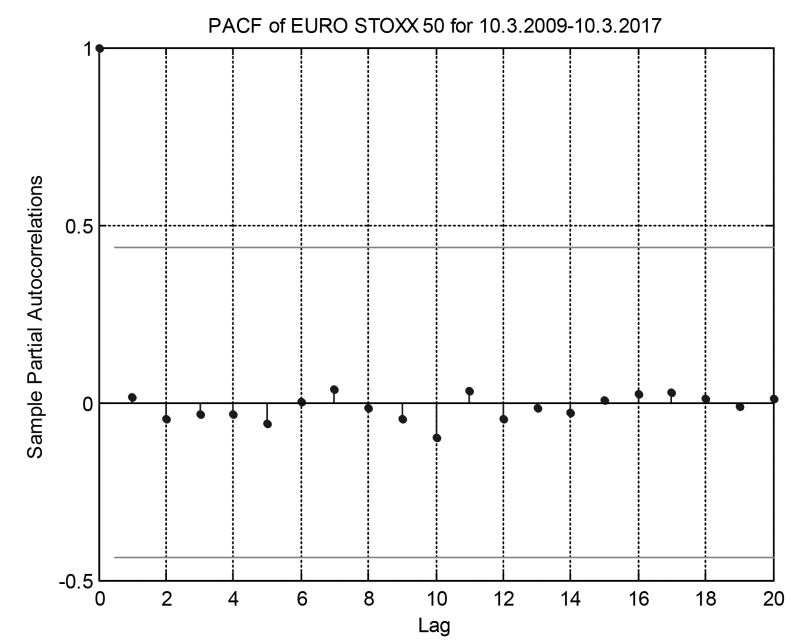

Figure 4: Graph of partial autoregressive (PACF) of shares for post-crisis period

The post-crisis period is the longest in the study - the observations cover the time interval from 10.3.2009 to 10.3.2017. After the financial crisis of 2008, reaching the bottom in share and index performance, the post-crisis period shows us the return for all to normal. The EURO STOXX 50 fail to regain its maximum levels, in contrast, the shares managed to stabilize their market performance at the levels of 2007. The autocorrelations as a value and graphical representation are close to those before the crisis (Figure 4). Partial autocorrelation has values close to the confidence interval, but they are statistically insignificant. There is even distribution without serial movements towards positive or negative lags, which is a direct indication of the validity of the ,weak" form of market efficiency according to the EMH.

\subsection{VOLATILITY TGARCH MODELLING}

\section{Volatility paradox existence at macro level - EURO STOXX 50 index}

Pre-crisis period. The results from the TGARCH modeling of the volatility in the pre-crisis period, both for the EURO STOXX 50 and for the shares that are included it, are presented in Table 1. The leverage coefficient values in the pre-crisis period are -0.0176 for positive news and 0.1266 for negative. The recorded values are fully in line with the assumption of VP in the pre-crisis period. The positive market news prevailing during this period leads to a decrease in market volatility.

The magnitude of volatility reduction by the positive news is lower than the negative news impact - in absolute terms, it's equal to 0.1090, but taking into account the prevailing positive market news during that period, this completely matches the assumption of PPs. Such a significant contrast difference between the impact of positive and negative news not only indicates VP but also contradicts EMH market-performance assumptions. Market index dynamics show efficiency, with the coefficient of persistence at the value of 0.9213 , to which we can add the relatively close value of the GARCH coefficient (0.9389), which represent the impact of volatility dynamics from past lags.

For the pre-crisis period, we can summarize that there is a relatively efficient market that does not fully translate the market trends of volatility from the previous periods but which shows the existence of VP. That resulting in volatility reduction made by the positive market news that is partially offset, even in a greater scale, by the negative news, which however has a lower frequency of manifestation. 
Post-crisis period. The results from the TGARCH modeling of the volatility in the post-crisis period, both for the EURO STOXX 50 and for the shares that are included it, are presented in Table 2. For the purpose of analyzing the change in the TGARCH coefficients from pre- to post-crisis period their values are presented and compare in Table 3.

Table 1: TGARCH results for the pre-crisis period

\begin{tabular}{|c|c|c|c|c|c|}
\hline $\begin{array}{c}\text { Shares / TGARCH } \\
\text { coefficients }\end{array}$ & $\begin{array}{c}\text { TGARCH } \\
\text { model }\end{array}$ & $\begin{array}{c}\text { Coefficient of } \\
\text { persistence }\end{array}$ & $\boldsymbol{\alpha}$ & $\boldsymbol{\alpha}+\boldsymbol{\gamma}$ & $\boldsymbol{\beta}$ (garch) \\
\hline Allianz & $1: 1$ & 0,898827 & 0,097044 & 0,105946 & 0,801783 \\
\hline Anheuser & \multicolumn{5}{|c|}{ It's not in the index for the period } \\
\hline Inditex & \multicolumn{5}{|c|}{ It's not in the index for the period } \\
\hline L'oreal & $2: 2$ & 0,423986 & 0,195985 & 0,178866 & 0,228001 \\
\hline LVMH & $1: 2$ & 0,875432 & 0,125262 & 0,101802 & 0,75017 \\
\hline Unilever & $1: 1$ & $0,938384+$ & $5,05 \mathrm{E}-05$ & $\begin{array}{c}5,05 \mathrm{E}-05+ \\
0,055516\end{array}$ & 0,938384 \\
\hline Sanofi & $1: 2$ & 1,007105 & 0,032471 & 0,003615 & 0,974634 \\
\hline SAP & $2: 2$ & 0,865925 & 0,113234 & 0,06471 & 0,752691 \\
\hline Siemens & $1: 1$ & 0,994186 & 0,036485 & 0,009159 & 0,957701 \\
\hline Total & $2: 1$ & 0,32938 & 0,059484 & 0,148468 & 0,269896 \\
\hline Average & & 0,770691571 & 0,08250194 & 0,087509429 & 0,709158 \\
\hline EURO STOXX 50 & $1: 1$ & 0,921307 & -0.017679 & 0,126682 & 0.938986 \\
\hline
\end{tabular}

Table 2: TGARCH results for the post-crisis period

\begin{tabular}{|c|c|c|c|c|c|}
\hline $\begin{array}{c}\text { Shares / TGARCH } \\
\text { coefficients }\end{array}$ & $\begin{array}{c}\text { TGARCH } \\
\text { model }\end{array}$ & $\begin{array}{c}\text { Coefficient of } \\
\text { persistence }\end{array}$ & $\boldsymbol{\alpha}$ & $\boldsymbol{\alpha}+\boldsymbol{\gamma}$ & $\boldsymbol{\beta}$ (garch) \\
\hline Allianz & $1: 1$ & 0,947455 & 0,013586 & 0,121733 & 0,933869 \\
\hline Anheuser & $1: 1$ & 0,932685 & 0,021075 & 0,092972 & 0,91161 \\
\hline Inditex & $2: 2$ & 0,276751 & 0,025366 & 0,012037 & 0,251385 \\
\hline L'oreal & $2: 2$ & 0,990276 & 0,003492 & 0,017358 & 0,986784 \\
\hline LVMH & $1: 1$ & 0,980465 & $-0,008182$ & 0,062065 & 0,972283 \\
\hline Unilever & $2: 2$ & 0,892642 & 0,174405 & 0,167628 & 0,718237 \\
\hline Sanofi & $1: 2$ & 0,992613 & 0,018693 & 0,017427 & 0,97392 \\
\hline SAP & $1: 2$ & 0,966937 & $-0,001106$ & 0,065727 & 0,968043 \\
\hline Siemens & $2: 1$ & 0,983758 & $-0,003607$ & 0,034162 & 0,987365 \\
\hline Total & $1: 1$ & 0,950254 & 0,002982 & 0,10597 & 0,947272 \\
\hline Average & & 0,8913836 & 0,0246704 & 0,069708 & 0,865077 \\
\hline EURO STOXX 50 & $1: 2$ & 0,951884 & -0.010051 & 0,098872 & 0,961935 \\
\hline
\end{tabular}


Finding and analyzing the manifestation of VP in the post-crisis period can be made by tracing the dynamics of the leverage and persistence coefficients in the context of their performance in the pre-crisis period. It is noteworthy that the impact of positive news in the post-crisis period leads to a decrease in market volatility in line with the assumptions of VP. As in the pre-crisis period, the coefficient is negative and with a relatively close value - from -0.0176 in the pre-crisis period to -0.0100 in the post-crisis period. However, the offsetting effect of negative news on the dynamics of volatility is limited compared to the pre-crisis period. The coefficient changes from 0.1266 prior to the 2008 crisis to 0.0988 in post-crisis conditions. This gives less impact of the negative market news on market volatility in post-crisis conditions. We can add to this all so the decreased market efficiency of the index. The coefficient of persistence marks an increase of 0,9213 in pre-crisis conditions of 0,9518 in the post-crisis period. The same we observe with respect to the GARCH coefficient from 0.9389 to 0.9619 . That way the worsened market efficiency is combined with the propensity of the index in post-crisis dynamics to more closely following the market trends in the volatility dynamics in comparison to the pre-crisis period. However, this worsened market efficiency does not lead to the formation of extremes in the incorporation of market news. The difference in the degree of the impact of the positive and negative news is lower than the pre-crisis period - from 0.1090 to 0.0888 . This shows a market situation in which decreased market efficiency leads to a stronger follow-up of the market trends by the volatility, but the existence of VP in the post-crisis period is less pronounced, as positive news continues to reduce market volatility to the relatively same extent as before crisis, but the offsetting effect of negative news, albeit with a smaller size, gets stronger support by the worsened market efficiency. Thus, when the negative market news is available in a positive market post-crisis trend, they have a less increasing effect to the market volatility in comparison with the pre-crisis period. But the worsened market efficiency leads to a more sustainable impact of the offset effect of negative news. This could also give us reason to believe that worsened market efficiency even enhances the offset effect of negative news as opposed to VP assumptions.

\section{Presence of volatility paradox at micro level-leading in market capitalization shares of EURO STOXX 50 index}

The assumption of the presence of VP at the micro level is subject to substantial corrections compared to the demonstrated at the macro level, i.e. as demonstrated by the market index. The leverage coefficients reflecting the impact of positive market news in both the pre-crisis and the post-crisis period have no negative value, as VP assumes. In the pre-crisis and benchmark for the existence of the VP period leverage coefficients for both positive and negative news are positive and close as values -0.08250 for the positive and 0.0875 for the negative ones. These coefficient values cover EMH assumptions that market news, whether positive or negative, should have a similar impact on market volatility. In this way, we could conclude that during the pre-crisis period, we cannot detect the existence of VP at the micro level of shares included in the studied index, unlike the index itself. Similar is the situation in the post-crisis period. The coefficients are positive, but with a greater difference between them and those from the pre-crisis period. Positive news leads to an increase in market volatility by 0.0247 and negative by 0.0697 .

This allows us to conclude that during the post-crisis period at the level shares included in the EURO STOXX 50, we cannot detect the existence of VP. At best, we can talk about a highly modified VP, where positive news and market trends do not lead to a reduction in volatility, but to its increase, albeit to a lesser extent than the impact of negative news.

The relativity of the VP existence, except in the context of pre-crisis and post-crisis market dynamics, could be outlined when we take into account the magnitude of its manifestation in macro 
and micro contexts. In the pre-crisis period, the difference in the values of the leverage coefficients in absolute terms is as follows:

- For the positive news, leverage coefficient of the index is approximately 7 times bigger in comparison with that of the shares;

- For negative news, the difference is approximately 4 times bigger in favor of the studied index.

In the post-crisis period, where is observed the weaker macro-level VP existence, these differences are weaker: for positive news, approximately one time, and for negative three times higher leverage coefficients for the index in comparison with the shares. This confirmation of VP's stronger existence in the EURO STOXX 50 index dynamics is also reinforced when we include in the analysis the level of market efficiency expressed through the coefficients of persistence and GARCH coefficients. In the pre-crisis period where the strongest VP existence is detected at the level of the index, the coefficient of the persistence of the shares is 0.1507 lower than that for the index.

This shows an increased market efficiency of the shares that leads to a significantly lower tendency for the shares to follow established market trends in contrast to the EURO STOXX 50. When we add to that and the relatively equal values of leverage coefficients for the shares, we can mark the overall efficiency of the shares fully in line with the assumptions of EMH. Not only we cannot detect the VP existence in the market dynamics of the shares, but the increased market efficiency leads to a lesser transfer of established trends in volatility than demonstrated by the index. If for the market index the GARCH coefficient has a value of 0.9389 , for the shares his value is 0.7091 .

Table 3: Change in TGARCH coefficients for the pre- to post-crisis period

\begin{tabular}{|c|c|c|c|c|c|c|c|c|}
\hline \multirow[t]{2}{*}{$\begin{array}{l}\text { Shares / TGARCH } \\
\text { coefficients }\end{array}$} & \multicolumn{2}{|c|}{$\begin{array}{l}\text { Coefficient of } \\
\text { persistence } \\
\quad(\alpha+\beta)\end{array}$} & \multicolumn{2}{|c|}{$\begin{array}{c}\alpha \\
\text { (reflects the } \\
\text { impact of positive } \\
\text { news) }\end{array}$} & \multicolumn{2}{|c|}{$\begin{array}{c}\alpha+\gamma \\
\text { (reflects the } \\
\text { impact of } \\
\text { negative news) }\end{array}$} & \multicolumn{2}{|c|}{$\begin{array}{c}\text { B(garch) } \\
\text { (reflects the } \\
\text { impact of } \\
\text { previous periods) }\end{array}$} \\
\hline & Pre- & $\begin{array}{l}\text { Post- } \\
\text { crisis }\end{array}$ & Pre- & $\begin{array}{l}\text { Post- } \\
\text { crisis }\end{array}$ & Pre- & $\begin{array}{l}\text { Post- } \\
\text { crisis }\end{array}$ & Pre- & $\begin{array}{l}\text { Post- } \\
\text { crisis }\end{array}$ \\
\hline Shares Average & 0,771 & 0,891 & 0,083 & 0,025 & 0,088 & 0,070 & 0,709 & 0,865 \\
\hline EURO STOXX 50 & 0,921 & 0,952 & -0.018 & -0.010 & 0,127 & 0,099 & 0.939 & 0,962 \\
\hline
\end{tabular}

\section{CONCLUSION}

The market dynamics of EURO STOXX 50 index proves the existents of volatility paradox, both in the pre- and the post-crisis period. For the post-crisis period, the presence of volatility paradox is less pronounced in comparison with the pre-crisis period. Positive news continues to reduce market volatility to the same extent as before the crisis, but the offset impact of negative news, albeit with a smaller size, gets stronger support from the worsened market efficiency.

During the pre and post-crisis period at the level shares included in the EURO STOXX 50, we cannot detect the existence of volatility paradox. At best, we can accept the existence of the highly 
modified volatility paradox in the post-crisis period, where positive news and market trends do not lead to a reduction in volatility, but to its increase, albeit to a lesser extent than the impact of negative news.

The relativity of the volatility paradox existence, except in the context of pre-crisis and post-crisis market dynamics, could be outlined when we take into account the magnitude of its manifestation in macro and micro contexts. Leverage coefficients, indicating the magnitude of incorporation of the positive and negative market news in volatility dynamics, are times bigger for the EURO STOXX 50 in comparison with that of its shares. This difference in the magnitude of incorporation of the market information declines in the post-crisis period, but remains relatively high and in favor of the index.

Studied shares of the EURO STOXX 50 index show higher market efficiency in the context of $\mathrm{EMH}$, which leads to a significantly lower tendency to follow established market trends in comparison to the index.

\section{REFERENCES}

Bhattacharya, S., C. Goodhart, D. Tsomocos, and A. Vardoulakis (2015). "A reconsideration of Minsky's financial instability hypothesis". Journal Money Credit and Banking Forthcoming.

Corradi, V., W. Distaso, and A. Mele (2013). Macroeconomic determinants of stock volatility and volatility premiums. Journal of Monetary Economics 60, 203-220.

Danielsson, Jon, Marcela Valenzuela, and Ilknur Zer (2016). "Learning from History: Volatility and Financial Crises," Finance and Economics Discussion Series 2016-093. Washington: Board of Governors of the Federal Reserve System, https://doi.org/10.17016/FEDS.2016.093

Fornari, F. and A. Mele (2009). Financial volatility and economic activity. Financial Markets Group Discussion Paper No. 642.

Hamilton, J., D. and G. Lin (1996). Stock market volatility and business cycle. Journal of Applied Econometrics 11, 573-593.

Hayek, F. (1960). The Constitution of Liberty. Routledge.

Minsky, H. (1992). The financial instability hypothesis. Working Paper 74, Jerome Levy Economics Institute, Annandale on Hudson, NY.

Schwert, G. W. (1989). Business cycles, financial crises, and stock volatility. Carnegie- Rochester Conference Series on Public Policy 31, 83-125.

Schwert, G. W. (1990). Stock volatility and crash of 1987. Review of Financial Studies 3, 77-102. 